\title{
Örgüt Kültürünün ve İşletme Demografisinin KOSGEB Desteklerine Etkisi: Burdur İli Araştırması*
}

\author{
The Effect of Organizational Culture and Business Demography on KOSGEB Supports: A Research in \\ Burdur
}

\author{
Ahmet SARITAŞ \\ Doç. Dr., Ankara Yıldırım Beyazıt Üniversitesi, \\ Şereflikoçhisar Uygulamalı Bilimler Fakültesi, \\ Uluslararası Ticaret ve Lojistik Yönetimi Bölümü, \\ asaritas@ybu.edu.tr \\ https://orcid.org/0000-0002-3580-5592
}

\section{Lütfullah BAKIR}

Uzman, KOSGEB Burdur Il Müdürlüğ̈̈

lutfullah.bakir@kosgeb.gov.tr

https://orcid.org/0000-0003-3232-4109
Makale Başvuru Tarihi: 20.07.2020

Makale Kabul Tarihi: 31.08.2020

Makale Türü: Araştırma Makalesi

\begin{abstract}
Anahtar
Kelimeler:

$K O B \dot{I}$,

$K O S G E B$,

Örgüt Kültürü,

Lojistik Regresyon

Modeli,

Örgüt kültürü bir örgütün bireyleri arasındaki inançları, beklentileri, aynı zamanda bu bireylerin davranışlarını düzenleyen ilkeler bütünüdür. Örgüt kültürü bireylerin, kitlelerin ve toplumların ihtiyaçlarını karşılamak için kurulan örgütlerin temel yapı taşı, sahip olduğu değerler, kabul ve kurallardır. Çevreleri ile sürekli bir alı̧̧veriş içinde olan örgütlerin, dinamizmini kaybetmemesi ve çevreyle entegrasyonunu sağlamak için birçok kamu kurum ve kuruluşu tarafindan destekler sağlanmaktadır. Bu kurumların başında da Küçük ve Orta Ölçekli İşletmeleri Geliştirme ve Destekleme İdaresi Başkanlığı (KOSGEB) gelmektedir. Bu çalışma ile örgütlerin örgüt kültürünün ve demografik yapılarının, KOSGEB desteklerinden yararlanmaları arasındaki ilişsi ortaya konulmaya çalıșılmıștır. Araştırmanın örneklemi, Burdur İlinde faaliyet gösteren ve KOSGEB Proje Tabanl Desteği alan KOBI'lerdir. Veri toplama yöntemi olarak anket tekniği seçilmiş olup, veriler ekonometrik bir model olan lojistik regresyon modeli ile yorumlanmıştır. Sonuç olarak, araştırmaya katılan KOBI'lerin örgüt kültürü ve demografik yapılarının, KOSGEB Proje Tabanlı Desteklerden yararlanmalarında kısmen iliş̧kili olduğu tespit edilmiştir.
\end{abstract}

Keywords:

SMEs,

$K O S G E B$,

Organizational

Culture,

Logistic Regression

Model,

\section{ÖZET}

\section{ABSTRACT}

Organizational culture is a set of principles that regulate the beliefs, expectations and behaviors of individuals within an organization. Organizational culture is the basic building block, values, acceptance and rules of organizations established to meet the needs of individuals, masses and societies. In order to ensure that the organizations that are in constant exchange with their environment, do not lose their dynamism and integrate with the environment, various supports are provided by many public institutions and organizations. Small and Medium Enterprises Development Organization (KOSGEB) is the leading institution providing such supports. The aim of this study is to reveal the relationship between the organizational culture and demographic structures of organizations and their use of KOSGEB supports. The sample of the research is the SMEs operating in Burdur province and receiving KOSGEB Project Based Support.The questionnaire technique was chosen as the data collection method and the data obtained were interpreted with logistic regression model which is an econometric model.As a result, it was found that the organizational culture and demographic structures of the SMEs participating in the research were partly related to their use of KOSGEB Project Based Supports.

* Bu makale ikinci yazarın, Doç. Dr. Ahmet SARITAŞ (birinci yazar) danışmanlığında hazırlanan ve 2019 yılında Burdur Mehmet Akif Ersoy Üniversitesi Sosyal Bilimler Enstitüsünde sunularak kabul edilen "Örgüt Kültürünün ve İşletme Demografisinin KOSGEB Desteklerine Etkisi: Burdur İli Araştırması” başlıklı yüksek lisans tezinden faydalanılarak hazırlanmıştır. 


\section{GIRISS}

Dünyada ve ülkemizde ekonominin lokomotifi haline gelen Küçük Orta Büyüklükteki İşletmeler'in (KOBİ) gün geçtikçe önemi daha da artmaktadır. Gelişmiş ülkelerin ortalama değerlerine bakıldığında KOBİ'lerin genel işletmeler içerisindeki payının \%99 olduğu ve istihdamın \%66'sını, yaratılan katma değerin ise \%48'sini sağladıkları görülmektedir. Bunun yanı sıra KOBI'lerin büyük ölçekli işletmelere nazaran daha geniş coğrafyalara nüfuz edebilme yetenekleri sayesinde bölge farklılıklarını azaltmak, gelir dağılımı ve ülke refah düzeylerini tabana yaymak gibi sosyal görevleri de bir o kadar önemlidir.

Toplum ve devlet için bu kadar önemli rol üstlenen birimlerin desteklenerek etkinliğinin ve verimliliğinin arttırılması şart olmuştur. Bu amaçla verilecek desteklerin özgün, ulaşılabilir, güncel ihtiyaçlara cevap verebilir olmalarının yanı sıra; dünya çapında, ulusal ve bölgesel pazarlarda rekabet kapasitesini arttıracak etkinlikte olmaları gerekmektedir.

Çalışma kapsamında, örgüt kültürü tanımlanmış olup, örgüt kültürünün işletmelerin amaç, hedef, vizyon ve faaliyetleri üzerine etkileri kültür modelleriyle açılanmaya çalışılmıştır. Ayrıca, KOBI'lerin sınıflandırılmasındaki nitel ve nicel ölçütlerden bahsedilmiş, bazı ülke ve birliklere ait KOBİ tanımlamaları yapılmıştır. Türkiye'deki güncel KOBİ tanımlaması yapılarak Küçük ve Orta Ölçekli işletmeleri Geliştirme ve Destekleme İdaresi Başkanlığı (KOSGEB) tanımlanarak KOSGEB destek programları ve amaç ve içerikleri anlatılmıştır. Uygulanma kapsamında ise örgüt kültürünün KOSGEB destekleri üzerine etkileri Ekonometrik bir model olan Lojistik Regresyon analizi ile incelenmiş, elde edilen sonuçlar yorumlanmaya çalışılmıştır.

\section{KAVRAMSAL AÇIDAN ÖRGÜT KÜLTÜRÜ}

Örgüt kavramı, birçok değişik bilim dalının (sosyoloji, antropoloji, kamu yönetimi gibi) alanına girmiş ve birçok değişik tanımları olan bir kavramdır (Şişman, 1994:39). Koçel'e göre örgüt; “iş ve iş, iş ile insan ve insan ile insan arasındaki düzen ve düzenlemeler" olarak tanımlanmaktadır (Koçel, 2001:97). Örgüt, bireylerin amacına ulaşmak için insanlarla bilinçli bir şekilde ortak çalışma yapmasının sonucudur.

Kültür kelimesi Latince'deki "culture"den gelmektedir. Ancak, bugünkü kullanılan anlamında kültür kelimesini ilk kez Voltaire kullanmıştır. Voltaire'ye göre "culture", "insan zekâsının oluşumu, gelişimi, geliştirilmesi ve yüceltilmesi" anlamına gelmektedir. Buradan Almancaya geçen sözcük ve 1973 y1lında yayınlanan Alman sözlüğünde "cultur" olarak kullanılmış, daha sonra farklı milletlerin dillerine de geçerek "kültür" haline gelmiştir (Güvenç, 2003:10). Kültür tarihi geçmişten gelmesinden dolayı toplumsal bir miras, bugüne kadar öğrendiğimiz maddi manevi kıymet, davranış şekillerimiz ve inanç bütünümüz şeklinde tanımlanabilir. Yani grubu oluşturan ve geliştiren bireylerin hayat bütünü olarak tanımlanabilir (Güvenç, 1996:96). Örgütün kurulmasından itibaren kurucular ve sonrasında örgüte katılan yeni üyelerin dış çevre ve kendi aralarında etkileşimleri sonucunda, örgütleri diğer örgütlerden ayrıştıran ve özgün kılan örgüt kültürü meydana gelmektedir. Edgar Schein örgüt kültürünü; "dış çevreye uyum gösteren grup tarafindan yine grubun içsel иyumu ve bütünleşmesi sırasında öğrenilen, olumlu çıktılarla sonuçlanan ve yeni üyelere aktarılabilen bilgi, birikim, tecrübe varsayımlarıdır", olarak tanımlamıştır (Schein, 1992:14).

Demirbilek (2005), işletme, firma, kurum kültürü olarak da ifade edilen örgüt kültürünün; çeşitli yönetim ve organizasyon kavramlarının ve tekniklerinin uygulanma ve başarı olasılıklarını etkileyebileceğinden, örgüt kültürü kavramının yönetim yaklaşımları ve tekniklerinin uygulanmasında dikkat edilmesi gerekliliğini ifade etmektedir (Demirbilek, 2005:75). Örgüt kültürü; Schwartz ve Davis'in (1981) yaklaşımına göre örgüt içerisinde yer alan bireylerce uzlaşılan inanç ve beklentilerin, yine örgüt içerisindeki bireylerin tavırlarını şekillendirerek normların oluşmasını sağlayan ilkeler bütünüdür (Murat ve Açıkgöz, 2007:3).

Her sosyolojik yapının özgün özelliklere sahip olmasından yola çıkılarak bu yapıyı oluşturan toplumun alt kavramı olan örgütlerinde temel özelliklerinin olduğu sonucuna varılmaktadır. Konuya ilişkin birçok araştırmacı kendine has tanımlar ve değerlendirmeler yapmıştır. Stephen ve Judge örgüt kültürünün özelliklerini yedi başl1k altında toplayarak açıklamaya çalışmıştır (Stephen ve Judge, 2009:585-586);

- Takım odaklılık: Örgütte yapılması gereken görevlerde ekip çalışmasının sonucu çıkan sinerjinin getirileri üzerine odaklanma.

- Detaya dikkat etme: Yapılan işlerde sıfır hataya yakın sonuç alacak şekilde sistem kurularak, detaylara en hassas şekilde dikkat edilmesi. 
- Yenilik ve risk alma: Örgüt içerisinde çalışanların girişimci, risk alma kapasitesinin yüksek olması ve yeni fikirlere modern yapıya açık olması.

- İnsan odaklılık: Lider ve örgütün aldığı, uyguladığı karar ve yöntemlerin çalışanlarda oluşacak etki geri bildirimlerinin algılanabilir olması.

- Sonuç odaklılı: Sonuca odaklanmak için uygulanan strateji ve taktiklerden ziyade, beklenti ve sonuca odaklanma.

- Saldırganlık: Örgütte çalışanların iş performanslarının arttırılması amacıyla rekabetçi olma seviyelerinin tanımlanması.

- Durağanlı: Örgütün niteliklerini geliştirmek için kullanmak istediği stratejilerin seçilmesi ve eyleme geçilmesi.

Örgüt kültürü, hem örgüt hem de örgüt bireyleri için çok önemlidir. Örgüt kültürü örgüt içerisindeki belirsizlikleri en aza indirerek, çalışanları görev ve sorumluklarını neyi, nasıl, nerede, kiminle yapılacağını belirlerken birtakım fonksiyonları da tanımlamaktadır.

\section{1. Örgüt Kültürünün Fonksiyonları}

Örgüt kültürü; hem örgüt hem de örgüt bireyleri için çok önemlidir. Örgüt kültürü örgüt içerisindeki belirsizlikleri en aza indirerek, çalışanları görev ve sorumluklarını neyi, nasıl, nerede, kiminle yapılacağını belirlerken birtakım fonksiyonları da tanımlamaktadır. Örgüt kültürünün fonksiyonları şu şekilde tanımlanmıştır (Özkalp ve Kırel, 1998:109);

- Örgüt üyeleri için bir otokontrol sistemidir. Diğer bir ifadeyle, örgüt üyelerinin davranış ve tutumlarını etkileyen bir kurallar bütünüyle bireylere etki edip yönlendirir.

- Örgüt bireyleri arasındaki dayanışmayı arttırıp, kaynaşmayı sağlamlaştırır.

- Örgüt üyelerinin kişisel değer ve çıkarlarından ziyade, bireylerin ortak ve daha üst değere bağlanmasını imkân verir.

- Üyelerine bir kimlik vererek örgüte, gruba aidiyet duygusu aşılar.

- Örgütü diğerlerinden farklı kılar.

Örgüt kültürü ile ilgili olarak başlıca örgüt kültürü modelleri şunlardır;

- Parsons (AGIL) Modeli

- Quinn ve Cameron (Rekabet Eden Değerler) Modeli

- Peters ve Waterman Modeli

- Goffee ve Jones (Çift S) Modeli

- Harrison ve Stokes Modeli

- Denison Modeli

Parsons geliştirdiği modelde her sosyal grupta sistemin sürekliliğini sağlamak için belli başlı görevleri yapması gerektiğini iddia etmiştir. Quinn ve Waterman Modeli; çalışanların değerlerini, bilgiyi işleme süreçlerini, düşünme tarzlarını ve varsayımlarını kullanan tanınmış ve kabul görmüş teknikliklerle uyumluluk göstermiştir. Peters ve Waterman modeli, işletmelerdeki başarıyı sağlayan faktörleri sekiz kültür, değer olarak tanımlamaktadır. Goffee ve Jones modelinde örgütler sosyalleşme ve dayanışma seviyelerine göre "Topluluksal", "Şebekeleşmiş", "Kâr Amacı Güden" ve "Bölümlenmiş" olarak dört örgüt kültür alt modeline ayrılır. Harrison ve Stokes modelinde örgüt kültürü, örgüt bireylerin gücü nasıl algıladıklarına ve kullanış biçimlerine göre kurgulamıştır (Bakır, 2019:11-16).

Çalışmanın uygulama bölümünde temelini Denison Örgüt Kültürü Modeli oluşturmakta olup, bu kapsamda Denison Modeli detaylı olarak çalışmada incelenmektedir. 


\subsection{Denison Örgüt Kültürüi Modeli}

Denison ve Mishra (1995), örgüt kültürünü ile ilgili çalışmaları için iki eksen tanımlamıştır. Birinci eksen örgüt kontrolü dışındaki çevreye uyum sağlayabilme, ikinci eksen ise bu örgüt dışındaki koşullara entegrasyonu sağlayabilmek için örgüt içerisindeki fonksiyonel ve yapısal değişiklileri gerçekleştirebilme becerisidir. Bu iki ana eksen kendi içerisinde de ikiye ayrılarak toplamda dört temeli oluşturur (Yahyagil, 2004). Denison'un ölçmeyi hedeflediği örgüt kültürünü şekillendirdiğimizde daireyi yatay olarak bölen eksenin üzerinde kalan alan örgütün dışa uyumunu, alt bölümde kalan alan ise örgüt içerisindeki ve örgüt üyelerine yönelik uyum yeteneğini ifade etmektedir. Daireyi dikey olarak bölen eksenin solunda kalan alan esneklik ve örgütsel değişimi, sağında kalan alan ise durağanlığı, stabiliteyi ifade eder. Daire içerisindeki eğilimine göre işletmenin kültür profilinin değişen diş ve iç koşullara ne kadar uyum sağlayabileceğini, işletmenin bu değiş̧imlere ne ölçüde esnek ve durağan olduğunu göstermektedir.

Şekil 1. Denison Modeli

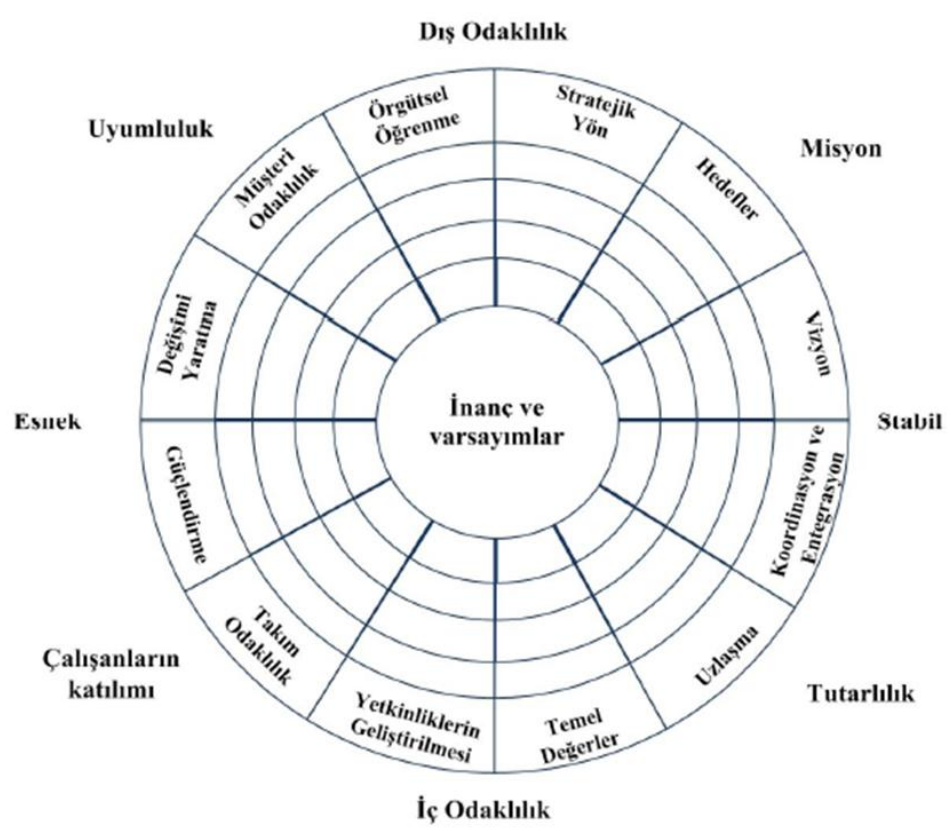

Geliştirilen modelde dört temel madde, bu dört temelle ilişkili on iki alt madde bulunmaktadır. Modeli oluşturan temel maddeler ve bunları oluşturan alt maddeler Tablo 1' de verilmiştir (Uzun, 2007:87).

Tablo 1. Denison'un Örgüt Kültürü Modelinin Temel ve Alt Boyutları

\begin{tabular}{|c|c|}
\hline TEMEL BOYUTLAR & ALT BOYUTLAR \\
\hline \multirow{4}{*}{ Çalı̧̧anların Katılımı } & Yetkinliklerin Geliştirilmesi \\
\cline { 2 - 2 } & Takım Odaklılık \\
\cline { 2 - 2 } & Güçlendirme \\
\hline \multirow{4}{*}{ Tutarlılık } & Uzlaşma \\
\cline { 2 - 2 } & Temel Değerler \\
\cline { 2 - 2 } & Koordinasyon ve Entegrasyon \\
\hline \multirow{4}{*}{ Uyumluluk } & Örgütsel Öğrenme \\
\cline { 2 - 2 } & Değişim Oluşturma \\
\cline { 2 - 2 } & Müşteri Odaklılık \\
\hline \multirow{2}{*}{ Misyon } & Hedefler \\
\hline & Stratejik Yön \\
\cline { 2 - 2 } & Vizyon \\
\cline { 2 - 2 } & \\
\hline
\end{tabular}

Kaynak: Yahyagil, 2004:59. 


\subsubsection{Denison Modelinin Temel Kavramsal Boyutları}

Denison modelinin temel kavramsal boyutları dört ana başlıkta toplanır. Bu ana boyutlar; misyon kültürü, uyumluluk kültürü, tutarlılık kültürü ve katılımcılık kültürüdür. Modelin temel kavramsal boyutlarını kısaca ele alacak olursak (Leidner vd., 2008'den akt.: Erkmen, 2010:90);

- Misyon Külttürü: İşletmenin temel, kuruluş, varoluş amacını vurgular. Uyumluluk kavramının aksine işletmenin varoluş, temel amacı stabiliteyi, durağanlığı temsil eder. Uyum ve değişim için örgütün kapasitesi önemsenmez.

- Uyumluluk Kültüriü: Dış çevredeki etkenlere bağlı olarak değişim potansiyeli ve gücünün yüksek olduğu kültürlerdir.

- Tutarlılık Kültü̈rü: Sistemler, kurallar, iç kontrol mekanizması ve davranışlar önemlidir. Bu kültür türü değişime en sert karşı durandır. Örgüt üyelerinin bağl1lı̆̆ kendi istekleriyle değil, iç kontrol mekanizmasının yönlendirdiği değerlerle mümkündür.

- Katılımcılık Kültürrü: Katılımcı olan kültürlerde örgüt amaç ve hedeflerine kendiliğinden gönüllü bağl1lık ve bireysel sahiplenme fazladır. Bu durum örgüt üyelerinin çok yoğun sorumluk ve özveri göstermelerini sağlar.

\subsubsection{Denison Modelininin Alt Kavramsal Boyutları}

Denison modelinde her bir temel kavramsal boyut kendi içerisinde üç alt kavramsal boyuta ayrılmaktadır. Tablo.1'de ayrıntılı olarak belirtilen bu alt boyutlar toplamda oniki adettir. İlgili alt boyutların kısaca ele alınmasinda yarar vardır.

- Vizyon: İleriye dönük fakat net bir şekilde ortaya koyulmuş, anlamlı işletme vizyonları çalışanların enerjisini artırmakta, örgüt hedefleri ve misyonu doğrultusunda örgüt üyelerini yaratıcı olmaya, işleriyle bütünleşmeye sevk etmektedir (Yahyagil, 2004:60-61).

- Temel Amaçlar: Stratejik eylemlerin bilinçli bir şekilde gerçekleştirilmesi ve misyon ve vizyonun belirginleşmesi örgütün uzun dönemde belirleyeceği amaçlarına bağlıdır.

- Stratejik Yönlendirme: Örgüt başarısının etkili olmasında örgüt amaçlarının ulaşılabilirliklerini arttırmak amacıyla tanımlanmış iş planlarının olması ve iş planlarına inançlı örgüt üyelerinin mevcudiyeti önemlidir.

- Örgütsel Öğrenme: İşletme çalışanlarının günümüzün hızlı değişen koşullarını, gelişen teknolojiyi ve yenilikleri deneyimlemeleri de dikkate alarak sürekli öğrenmeye açık olmaları örgütün başarısını ve sürekliliğini etkiler. Örgüt misyonlarının net bir şekilde açıklanması, örgüt üyelerinin bu misyonu kavrayarak örgüt amaçlarının nasıl gerçekleştirileceği hakkında olumlu etkiler yaratmaktadır.

- Müşteri Odaklılık: İşletmelerin kalite standartlarına bağlı olmaksızın, faaliyet alanları içerisindeki potansiyel ve hali hazırdaki müşterilerinin beklenti, ihtiyaç ve isteklerinin karşılanması çok önemli bir husustur.

- Değişim Yaratma: İşletmelerin diş koşullara uyum sağlayabilen yaratıcı, gerçekçi değişiklik yapması günümüzde vazgeçilmez bir zorunluluktur.

- Işs-Birliği ve Bütünleşme: İşletme hiyerarşisinde yer alan tüm çalışanların amaçlara, hedeflere ulaşabilmek için aldıkları karar, ilke ve yöntemler birliği esasıdır.

- Uzlaşma: Çalışanların işletme hedeflerine ve bunlara ulaşma yöntemleri açısından kullanılan düşünce ve eylemlere uzlaşısı olması gerekmektedir.

- Temel Değerler: Örgütün kurucuları tarafından belirlenmiş, sürdürülen, vazgeçilmez, temel örgüt özelliklerini ve değerlerini kapsar.

- Yetenek Gelişstirme: Örgüt amaçlarını gerçekleştirmek için çalışanların yeteneklerini geliştirmesi, verilecek yönetici desteği, eğitim ve destekleri ifade etmektedir. 
- Takım Çalışması: İşletmenin ulaşmak istediği temel amaç, faaliyetlere belli nitelikteki örgüt üyelerinin uzlaşı ve sinerji yaratarak ortak karar alması, çalışanların süreci benimseyerek daha verimli olmasının sağlanmasıdır.

- Yetkilendirme: Örgüt üyelerinin sorumluluk duygularını ve örgüte bağlılıklarını arttırmak, işleriyle bütünleşmesini sağlamak, yaptıkları işe ilişkin yetkilenlendirmeyle kuvvetlenmektedir.

\section{KOBİ, KOSGEB VE KOSGEB DESTEKLERI}

Dünyada olduğu gibi ülkemizde de ekonomik yapının temel taşlarını, küçük ve orta ölçekli işletmeler (KOBİ) oluşturmaktadır. Üretilen katma değerin, istihdamın, teknolojik ilerlemenin, bölgesel kalkınma ve refah seviyesinin yükseltilmesinde KOBİ'ler önemli görevler üstlenerek lokomotif işlevi görmektedir. Küreselleşmenin etkisini yoğun bir biçimde hissettirdiği ve Avrupa Birliği üyeliği yolunda çalışmaların tekrar ivme kazandığı son zamanlarda, KOBI'ler için bazı firsat ve tehditler ortaya çıkmakta olup, ekonomik kalkınma ve büyüme döneminin başlangıcında inanılanın aksine KOBİ'lerin önemi daha da önem kazanmıştır (Karakoç, 2010:1).

KOBİ'lerin ülkeler ve kurumlar tarafından tanımlanmasında kullanılan ölçütler genel olarak "nicelik (kantitatif) ölçütler" ve "nitelik (kalitatif) ölçütler" diye iki ana grupta değerlendirilir. Ekonomik/finansal organizasyonlar, ulusllararası kuruluşlar ve devletler tarafindan iki ana grupta bulunan ölçütler (kıstaslar) farklı parametrelerle tekil ya da karma bir şekilde formüle edilerek KOBİ tasnifinde ve dolayısıyla tanımlamasında kullanılmaktadır. Ancak piyasa koşulları, politik yaklaşımlar, entegrasyon, vd. nedenler ile ülkeler ve kuruluşların esas aldıkları kriterlerde değişikliklere gidilebilmektedir. Bu durum evrensel olan bu ölçütlerin KOBİ tanımlamasındaki etki düzeylerini (kullanım oranları, öngördükleri sayısal sınırları, oranları, vs.) sektörlere, coğrafyaya ve tarihsel dönemlere göre değişken bir hale getirerek genel kabul görmüş, kapsayıcı bir KOBİ tanımının (tasnifinin) yapılmasına da engel olmaktadır (Mecek, 2020:30).

Ülkeler, KOBİ tanımlarını, politikaları ve kaynakları çerçevesinde sermaye büyüklüğü, isçi sayısı ve ciro gibi belirleyici unsurlardan bir ya da birkaçını kullanarak belirlemektedirler. Tanım oluşturmada genel olarak gelişmiş ülkelerin, ciro, sermaye ve çalışan isçi sayısı ölçütlerini birlikte kullanarak KOBİ tanımlarını oluşturdukları görülmektedir (Ar, 2009:24).

\section{1. Çeşitli Ülkelere ve Birliklere Göre KOBİ Tanımı}

Başta Dünya Bankası, Ekonomik İşbirliği ve Kalkınma Teşkilatı (OECD), Avrupa Birliği, Birleşmiş Milletler, Asya Kalkınma Bankası ve Afrika Kalkınma Bankası gibi uluslar arası/uluslarüstü kuruluşlar ile ABD, İngiltere, Fransa, Almanya, İtalya, Hollanda, Japonya, vd. ülke mevzuatlarında Kobi tanımları1 yapılmıştır. Birbiri ile sıkı ekonomik ilişkiler içerisinde olan ya da aynı ekonomik toplulukta yer alan devletlerin kobi tanımlarının birbirine daha yakın hatta bazen ortak olduğu görülmektedir. Ancak genel anlamda genel kabul görmüş, kapsayıcı ve evrensel bir kobi tanımı bulunmamaktadır. Örnek olması açısından bazı kuruluş ve ülke kobi tanımlarının belirtilmesinde yarar vardır.

OECD, işletme çalışan işçi sayısına göre işletmeleri sınıflandırmaktadır. 0-19 işçi çalıştıran işletmeler çok küçük, 20-99 işçi çalıştıran işletmeler küçük, 100-499 işçi çalıştıran işletmeler orta ölçekli, 500'den daha çok sayıda işçi çalıştıran işletmeler ise büyük ölçekli işletme sayılmaktadır (Müftüoğlu, 2002:119).

Avrupa Birliğindeki ilk KOBİ tanımı 1996 yılında yapılmıştır. Değişen ve gelişen dünya şartları, teknolojik değişimler ve enflasyonun etkisiyle 2005 yılında yeniden tanımlamaya ihtiyaç duyulmuştur. $A B$ tanımı yaparken 3 faktörü temel almıştır. Bunlar; ciro, net satışlar ve işletmede çalışan işçi sayısıdır (Bakır, 2019:23).

ABD'de özellikle küçük işletmelere bilgi ve finansman desteği sunan ve federal bir kuruluş olan SBA (Small Business Administration) Küçük İşletmeler İdaresi ölçek standartlarını belirlerken NAICS (North American Industrial Classification System) Kuzey Amerika Endüstri Sınıflandırma Sistemini kullanmaktadır. Bu sisteme göre de sektörel olarak işletmelerin satış tutarları ve çalıştırılan işçi sayılarına göre bir tasnifleme yapılmaktadır (Maden, 2012:14).

Japonya'da KOBİ'ler tanımlanırken çalışan sayısı ve sermaye miktarları dikkate alınmaktadır (http://www.chusho.meti.go.jp/). Sektör bazında yapılan tanımlamaya göre örneğin imalat sanayinde 300'den az

1 Dünyada Kobi tanımları ve tanımlama ölçütleri konusunda daha geniş ve detaylı bilgi için Bkz.: Mecek, 2020:37-49. 
çalışanı olan ve sermaye miktarı 300 milyon yeni geçmeyen işletmeler KOBİ kabul edilmektedir. Japonya'da ABD'de olduğu gibi sektörel ölçeğe göre daha ayrıntılı bir tanımda, üretim sektöründe 5 kişiden az işçi çalıştıran işletmeler mikro, 20 kişiden den az isçi çalıştıran işletmeler çok küçük, 20 ile 299 arasında işçi çalıştıran işletmeler Küçük ve Orta Boy İşletme olarak kabul edilmektedir (Çakıroğlu, 2008:9).

\subsection{Türkiye'de KOBİ Tanımı ve KOBİ'lerin Gelişimi}

Türkiye'de 2005 öncesi birçok kurumun kendi KOBİ tanımının olması kafa karışıklığına yol açmakta, politika ve desteklerin uygulama alanlarında sorunlara yol açtı̆̆ görülmektedir, bu nedenle genel bir KOBİ tanımının yapılması zorunlu hale gelmiştir. Ülkemizde 18 Kasım 2005 tarih ve 25997 sayılı Resmi Gazetede "Küçük ve Orta Ölçekli İşletmelerin Tanımı, Nitelikleri ve Sınıflandırılması Hakkındaki Yönetmelik" ile ilgili 2005/9617 sayılı Bakanlar Kurulu kararı yayınlanmış ve Nisan 2006 tarihinde yürürlüğe girmiştir. Bu tanımlamaya göre; yıllık ortalama çalışan sayısı ve net satış hasılat veya bilanço baz alınmıştır (http://www.resmigazete.gov.tr, 25.9.2018).

KOBİ tanımlaması yaparken işletmenin Limited, Anonim, Kolektif, Komandit, Şahıs gibi yasal statüsü ne olursa olsun; 10 kişiden az çalışanı olan ve yıllık net satışı veya bilanço değeri 1 milyon TL'nin altındaki işletmeler mikro; 10 ila 50 arasında çalışanı, net satış hâsılatı veya bilançosu 1 ila 5 milyon TL arasında olanlar küçük; 50 ile 250 arasında işçi bilanço değeri veya net satılı 5 ila 25 milyon TL arasında olan işletmeler ise orta ölçekli işletme olarak kabul edilmiştir. Tespitte çalışan sayısı ve net satış hâsıla veya bilanço değeri temel alınmıştır (http://www.resmigazete.gov.tr/, 25.09.2018).

Gelişen dünya piyasaları, teknoloji ve görece artan enflasyon karşısında KOBİ tanımı revize edilmesi şart olmuş ve "Küçük ve Orta Ölçekli İşletmelerin Tanımı, Nitelikleri ve Sınıflandırılması Hakkındaki Yönetmelik" 4 Kasım 2012 tarih ve 28457 sayılı Resmi Gazete ile güncellenmiştir. Bu güncellemeyle net satış hâsılat ve bilanço değerleri yükseltilmiş ve KOBİ tanımına uyan işletme sayısı artmıştır. İki yüz elli kişiden az yıllık çalışan istihdam eden ve yıllık net satış hâsılatı veya mali bilançosundan herhangi biri kırk milyon Türk Lirasını aşmayan ve ilgili yönetmelikte mikro işletme, küçük işletme ve orta büyüklükteki işletme şeklinde sinıflandırılan ekonomik birimler olarak değiştirilmiştir (http://www.resmigazete.gov.tr/, 25.09.2018).

\subsubsection{Türkiye'de KOBİ'lerin Gelişimi}

Türkiye Cumhuriyeti'nin kurulması ile birlikte küçük ve orta büyüklükteki işletmelerin (KOBİ'lerin) tarihsel gelişim süreci üç ana dönemde ele alınmaktadır. Bu üç dönemde keskin ayrılışlar söz konusu olmasa da içinde bulunulan koşullara göre muhtelif farklılıkları ortaya koymaktadır. Buradan hareketle Kobi'lerin Türkiye'deki tarihsel gelişim sürecini "1923 - 1950 dönemi", "1950 - 1980 dönemi” ve "1980 sonrası dönem" olarak genel hatları ile ayrı ayrı ele alınacaktır.

- 1923-1950 Dönemi: Büyük ve orta ölçekli sanayi işletmelerinin kurulması ve işletilmesi için gereken tecrübe, bilgi birikimi ve teknolojinin özel sektörde bulunmayış1 gibi sebepler, devleti ister istemez ekonominin içine sokmuş, 1933 ve 1935 Sanayi Planı'nın uygulanmasıyla kurulan İktisadi devlet teşekküllerinin ekonomi içindeki payı artmıştır (Aykaç ve Parlak, 2008:135). Bunlara rağmen KOBI'lerin temeli girişimcilik ve özel sektörün desteklenmesinden vaz geçilmemiş bunun için Teşvik-i Sanayi Kanunu, Ticaret ve Sanayi Odaları Kanunu çıkarılmış, Sümerbank ve Türkiye Halk Bankası kurulmuştur. Bu dönemde ilk kez yapılan Genel Sanayi ve İşyerleri Sayımı sonuçlarına göre 1927 yılında 65.245 işletmenin faaliyet gösterdiğini ve bu işletmelerde 65.245 kişinin istihdam edildiğini istatistiksel olarak ilk kez kayda alıyoruz (Cilloy, 1954:180).

- 1950-1980 Dönemi: 1950-1980 yılları arası; Türk siyasi tarihinin karışık olmasıyla birlikte görece KOBİ'ler için ilk ciddi adımların atıldığı bir dönemdir. 1960 yılında Devlet Planlama Teşkilatının kurulmasıyla planlı ekonomiye geçişin ilk adımları atıldı. 1963 - 1977 arasındaki yıllar, "ithal ikamesi" yoluyla sanayileşmenin altın dönemi olmuştur. DPT özel sektör tarafından alınan kararlarda önemli bir rol oynuyordu. Bu tarihler arasına 3 tane Kalkınma Planı sığdırılmış, KOBI'ler için önemli adımlar atılmıştır. Birkaç tane örnek vermek gerekirse 507 sayılı "Esnaf ve Sanatkârlar Kanunu" kabul edilmiş (1964), KÜSGEM kurulmuş ve Sanayi bölgeleri ve sanayi siteleri kurulması çalışmalarına başlanılmış ve birçoğu faaliyete geçmiştir. Bu tercih ülkemize hem reel sektörün gelişimini olumsuz etkilemiş hem de ülke ekonomisine krizlerle ağır bedeller ödetmiştir. 1963 yılında yapılan Genel Sanayi ve İşyerleri Sayımı sonuçlarına göre ülkemizde 160.771 sınai işletmesinin olduğunu bunun \%98 inin KOBİ 157.759 
vasfinda olduğunu rapordan anlamaktayız. Sınai işletmelerine ek olarak 20104 toptan, 134.163 işletmeninde perakende sektöründe faaliyet gösterdiğini görüyoruz. Genel olarak 1963 y1lında yapılan Genel Sanayi ve İşyerleri Sayımı sonuçlarına göre ülkemizde kısmide olsa hedef kitlemiz olarak tanımlayabileceğimiz 312.026 işletmenin varlığını biliyoruz (Aykaç ve Parlak, 2008:137).

- 1980 Sonrası Dönem: 1980 Sonrası Y1llar; hükümet krizleri ve 1980 Askeri darbesi sonrası Türkiye ciddi bir şekilde sermaye zaman ve yetişmiş insanı kaybetmiş̧ir. Ardından tekrar geçilen demokrasi sürecinde ki yine de bu toparlanma 1990 yılların başına kadar devam etmiştir özel teşebbüslere ağırlık verilmeye başlanmış. Devlet politikalarıyla bu süreçler desteklenmiştir. İthal ikameci politikalar, yerini ihracata dayalı kalkınma modeline geçilmesi nedeniyle KOBİler de bir uyum dönemi yaşamıştır. KOBI'lere yönelik destek ve teşvikler ve bu amaçla gerçekleştirilen düzenlemeler daha da genişletilmiş, Yedince Beş Yıllık Kalkınma Planı döneminde (1996-2000), KOBİ'lere verilen önemi belirtmek üzere, 1996 yılı "KOBI Y1lı" olarak ilan edilmiştir. KOBİ'lerin proje kültürü, finansman, organizasyon ve teknoloji alanlarında desteklenmesi, girişimcilik eğitimi verilmesi bu Plan'da da yer almıştır. Sekizinci Beş Yıllık Kalkınma Planı döneminde ise (2001-05) KOBİ'ler Kredi Garanti Fonu, Risk Sermayesi, Finansman Yatırım Ortaklığı, Gayrimenkul Yatıım Ortaklığı gibi modern finansman araçları ve kurumlarıyla desteklenmiştir. 1983 yılında KÜSGET ardından KOSGEB kurulmuştur.

2013 y1lında düzenlenen TUİK verilerine göre 2011 yılı içerisindeki ülkemizde imalat ve hizmet sektöründe faaliyet gösteren işletme sayıs1 2.591.082'dir, bu sayının \%99,9 KOBİ'dir. İstihdamın \%76'sını, maaş ve ücretlerin \%53'ünü, cironun \%63'ünü, faktör maliyetiyle katma değerin (FMKD) \%53,3'ünü ve maddi mallara ilişkin brüt yatırımın \%53,7'sini oluşturdu (http://www.tuik.gov.tr/, 22.09.2018). Bu bile Türkiye'nin son 10 yılda ciddi ekonomik kalkınma hamlesi yaptığının bir işaretidir.

Şekil 2. Ekonomik Faaliyetlere Göre Girişim Sayısı ve İstihdamın Dağılımı, 2011

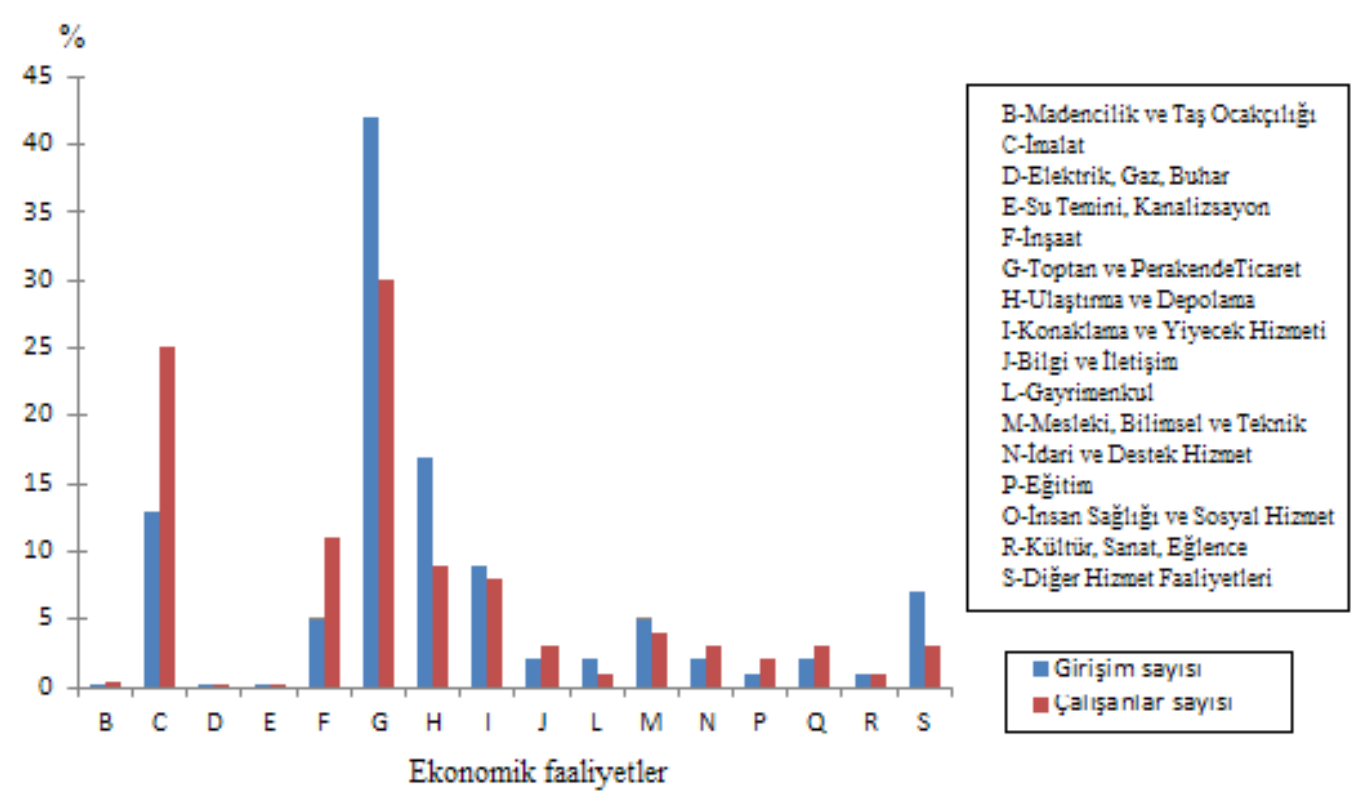

Kaynak: TUİK, 2013.

İhracatta; 1-9 kişi çalışan mikro ölçekli girişimlerin payı \%20,6 iken, 10-49 kişi çalışan küçük ölçekli girişimlerin pay $\% 24,3,50-249$ kişi çalışan orta ölçekli girişimlerin pay1 $\% 17,7,250+$ kişi çalışan büyük ölçekli girişimlerin payı ise \%37,2'dir. Girişimin ana faaliyetlerine göre ihracat değerinin \%34,9'u sanayi, \%60,1'i ticaret sektöründe faaliyet gösteren KOBİ'ler tarafından yapılmıştır. KOBİ'ler toplamda ülke ihracatının \%62.62'sini gerçekleştirmiştir. Yine 2012 yılında İthalatta; 1-9 kişi çalışan mikro ölçekli girişimlerin pay1 \%6,2, 10-49 kişi çalışan küçük ölçekli girişimlerin payı \%14,3, 50-249 kişi çalışan orta ölçekli girişimlerin payı $\% 17,9,250+$ kişi çalsşan büyük ölçekli girişimlerin payı ise \%61,4 olmuştur. İşletme ana faaliyetlerine göre ithalat değerinin \%33,2'si sanayi, \%55,7'si ticaret sektöründe faaliyet gösteren KOBİ'ler tarafindan gerçekleştirilmiştir. KOBİ'ler toplamda \% 38,5 oranında ithalat gerçekleştirmişlerdir. İthalatta yine ciddi bir payı teknolojik değeri yüksek bilgisayar, cep telefonu, tablet ve binek araçlar oluşturmaktadır. Bu rakamlar az 
da olsa yapısal bir sorun olduğunu göstergesi. Yeni ticaret, vergi ve bankacıllk sektöründeki düzenlemelerle aşağıya çekilmeye çalışılmakta ve sonuç alınmaya başlanmıştır (http://www.milliyet.com.tr/, 24.09.2104).

KOBI'lerin ülke gruplarına göre 2012 yılında dış ticaret incelendiğinde, KOBİ'ler tarafından yapılan ihracatın $\% 43,9$ 'u Avrupa ülkelerine, \%42,2'si Asya ülkelerine gerçekleştirildi. İthalatta ise KOBİ'ler yine Avrupa $(\% 51,2)$ ile Asya $(\% 37,9)$ ülkelerinden yapılan ithalatta önemli paya sahiptir. Bu mevcut ülkelerde Türk KOBİ'lerinin ürün ve firma bilinirliliği artmış yeni pazarlar arayışına girme hız kazanmıştır. Özellikle de vizelerin kaldırılması ve ülkelerle yapılan serbest ticaret anlaşmaları yeni pazarların kapısını sonuna kadar açmış, Afrika kıtası ülkelerine de hızla ihracat kapasitemiz artmıştır (http://www.sabah.com.tr/, 24.09.2104).

$\mathrm{Bu}$ bağlamda yeni işletmelerin kurulması ve mevcut işletmelerin varlığını devam ettirmesi sadece makro göstergelerin istikrarlı, ciddi ve etkin kullanılması ve yönlendirilmesi ile mümkündür. Ülkemizin 2000 yılında girdiği krizinden bu yana ciddi yapısal değişiklikler yapılmış, kontrollü enflasyon ve faiz politikalarıyla istikrarlı büyüme yakalanmıştır. Jeopolitik konumu ve güvenilir ekonomisiyle ülkemiz girişimcileri son yıllarda atağa kalkmıştır. Unutmamalıdır ki Girişimcilik ve girişimler, gelişmişliğin ve gelişme hızının en önemli göstergelerinden birisidir. Gelişmişlik düzeyinin korunması ve gelişme hızının artırılması ile toplumdaki girişimcilerin sayısı ve toplumu oluşturan fertlerin girişimcilik eğilimleri arasında paralellik bulunmaktadır. Toplumumuzda, gelişmekte olan diğer ülkelere oranla girişimcilik potansiyelinin daha yüksek olduğu açıtır (Derin vd., 2013:65).

\section{KOSGEB'İN TARİHSEL GELIŞSIMI VE KOSGEB DESTEKLERİ}

\subsection{Kurumsal Yapısı ve Faaliyetleri Açısından KOSGEB}

KOSGEB'in kuruluşundan başlayarak günümüze kadarki gelişim süreci mevzuatça değerlendirilmiş ve KOSGEB destekleri ana hatlarıyla anlatılmıştır. KOBI'lerin ekonomik ve sosyal bakımdan önemi I. Dünya savaşındaki devlet ve halkın tüm ihtiyaçlarının yine devlet tarafından karşılanamayacağı hissedilmiş II. Dünya Savaşı döneminde ise netlik kazanmıştır. KOBİ'lerin toplum ve devlet ihtiyaçlarını karşılamaktaki hızı ve esnekliği, ekonomide yarattığı istihdam ve katma değer etkisiyle, özelliklede globalleşmeyle, ülkeleri küçük ve orta ölçekli işletmeleri korumaya ve desteklemeye yönelik tedbirler almaya yöneltmiştir. Savaş sonrası dönemde, ekonomik canlılığı arttırabilmek için ülkeler KOBİ'leri korumak ve desteklemek için politikalar üretmeye başlamış KOBİ'lerin talep ve ihtiyaçlarını karşılamaya yönelik dolaylı ve doğrudan destek mekanizmaları geliştirmişlerdir. Söz konusu destekleri KOBİ'lerin ihtiyaç duyduğu biçimde ulaştırabilmek için devletler hizmet alt yapılarını ülke ve toplum geneline yayılabilecek şekilde oluşturmaya önem göstermişlerdir. KOBİ'lerin desteklenmesine yönelik uygulama ve çalışmalar geliştirilmesi özellikle 1950" li yıllardan başlayarak 1990'lı yılların başına kadardır devam etmiştir (Cansız, 2008:7).

1980 Sonrası Yıllar; hükümet krizleri ve 1980 Askeri darbesi sonrası Türkiye ciddi bir şekilde sermaye zaman ve yetişmiş insanı kaybetmiştir. Ardından tekrar geçilen demokrasi sürecinde ki yine de bu toparlanma 1990 yılların başına kadar devam etmiştir özel teşebbüslere ağırlık verilmeye başlanmış. Devlet politikalarıyla bu süreçler desteklenmiştir. İthal ikameci politikalar, yerini ihracata dayalı kalkınma modeline geçilmesi nedeniyle KOBİler de bir uyum dönemi yaşamıştır. KOBİ'lere yönelik destek ve teşvikler ve bu amaçla gerçekleştirilen düzenlemeler daha da genişletilmiş, Yedince Beş Yıllık Kalkınma Planı döneminde (1996-2000), KOBİ'lere verilen önemi belirtmek üzere, 1996 yılı "KOBI Yılı" olarak ilan edilmiştir. KOBİ'lerin proje kültürü, finansman, organizasyon ve teknoloji alanlarında desteklenmesi, girişimcilik eğitimi verilmesi bu Plan'da da yer almıştır. Sekizinci Beş Yıllık Kalkınma Planı döneminde ise (2001-05) KOBİ'ler Kredi Garanti Fonu, Risk Sermayesi, Finansman Yatırım Ortaklığı, Gayrimenkul Yatırım Ortaklığı gibi modern finansman araçları ve kurumlarıyla desteklenmiştir. 1983 yılında KÜSGET ardından KOSGEB kurulmuştur.

Türkiye'de bu süreç özellikle 1980 sonrası serbest piyasa ekonomisine geçiş dönemine girmesiyle, KOBİ'lerin varlığını sürdürebilmeleri ve desteklenmelerine yönelik uygulama ve yapılanmaların zaruri olduğu ve büyük kısmının devlet eliyle yapılması gerektiğini ortaya koymuştur. Türkiye'de 1990 yılında 3624 Sayılı Kanun ile ülkenin ekonomik ve sosyal ihtiyaçlarının karşılanmasında küçük ve orta ölçekli işletmelerin payını ve etkinliğini artırmak, rekabet güçlerini ve düzeylerini yükseltmek, sanayide entegrasyonu ekonomik gelişmelere uygun biçimde gerçekleştirmek amacıyla Küçük ve Orta Ölçekli İşletmeleri Geliştirme ve Destekleme İdaresi Başkanlığı (KOSGEB) kurulmuştur (Resmi Gazete, 1990:1).

3624 sayılı KOSGEB Kuruluş Kanunu'nda Değişiklik Yapılmasına Dair 5891 sayılı Kanun'un 5 Mayıs 2009 tarih ve 27219 sayılı Resmi Gazetede yayınlanmasıyla, ticaret ve ticaret sektörlerinde faaliyet gösteren KOBİ'ler de KOSGEB'in desteklediği sektörlere dâhil edilerek KOSGEB'in ülkemizde KOBİ'lerden sorumlu 
lokomotif kuruluşu haline gelmiştir (KOSGEB Stratejik Plan, 2011:2). KOSGEB; Bilim, Sanayi ve Teknoloji Bakanlığının ilgili bir kuruluşu olup, 5018 sayılı Kamu Mali Yönetimi ve Kontrol Kanununun II sayılı cetvelinin B bölümünde sayılan özel bütçeli bir kamu kurumudur. (KOSGEB Faaliyet Raporu, 2018:1).

\subsection{KOSGEB'in Temel Misyonu}

KOSGEB'in temel misyonu kısaca şu hali ile özetlenebilmektedir (KOSGEB Performans Programı, 2017:25);

- KOBİ'lerin üretim ve yönetim becerilerini, yenilikçi ve yüksek katma değerli ürün/hizmet üretme kapasitelerini geliştirmek ve uluslararası pazarda rekabet güçlerini artırmak,

- Girişimcilik kültürünü yaygınlaştırarak, geliştirmek ve sürdürülebilirliğini arttırmak,

- Kurumsal yapı ve algıyı güçlendirerek nitelikli hizmet sunma kapasitesini arttırarak ekonomik ve sosyal kalkınmadaki paylarını arttırmak,

- Sanayide entegrasyonu sağlayarak iktisadi ve teknolojik konjonktüre uygun biçimde gerçekleştirecek, destek ve hizmetler sunmak,

$\mathrm{Bu}$ stratejik amaçlar doğrultusunda son yıllarda yapılan düzenlemeler ve uygulamalarla katma değeri düşük sektörlerden ziyade daha stratejik, nitelikli ürünleri üreten işletme ve sektörler için gerekli desteklerin kurum olarak sunulması ve bu sektörlerde faaliyet gösterecek girişimcilerin yaygınlaştırılarak desteklenmesi, KOSGEB faaliyetlerinin verimli şekilde yürütülmesi, kaynaklarının korunması, mali bilgi ve raporlamaların zamanında ve güvenilir olarak üretilmesi amaçlanmaktadır.

\subsection{KOSGEB Destekleri}

Türkiye iktisadi varlığının \%99'unu KOBİ'ler oluşturmaktadır. Bakanalar kurulunca karara bağlanmış sektörler için kullandırılmış, kullandırılacak destek kalemleri aşağıdaki gibidir. Burada yer alan destek kalemlerinden bazıları yürürlükten kalkmış ve ikame niteliğinde olan destek Programları eklenmiştir. KOSGEB kurulduğundan bu zamana birçok destek vermiş değişen piyasa koşullarına ve işletme ihtiyaçlarına göre desteklerini revize etmiştir. Bu destek programlarından bazıları şunlardır;

- Girişimciliği Geliştirme Destek Programı (Girişimcilik Destek Programı),

- İşletme Geliştirme Destek Programı (Genel Destek Programı)

- İşbirliği Destek Programı,

- KOBİGEL - KOBİ Gelişim Destek Programı (KOBİ Proje Destek Programı),

- Ar-Geveİnovasyon Destek programı

- Endüstriyel Uygulama Destek Programı,

- KOBİ TEKNOYATIRIM - KOBİ Teknolojik Ürün Yatırım Destek Programı

- Stratejik Ürün Destek Programı

- TEKNOPAZAR- Teknolojik Ürün Tanıtım ve Pazarlama Destek Programı,

- Uluslararası Kuluçka Merkezi ve Hızlandırıcı Destek Programı,

- Gelişen İşletmeler Piyasası Kobi Destek Programı,

- Tematik Proje Destek Programı,

- Kredi Faiz Desteği ve Laboratuvar Hizmetleri'dir 


\section{5. ÖRGÜT KÜLTÜRÜNÜN VE IŞSETME DEMOGRAFİSININ KOSGEB DESTEKLERINE ETKİSI: BURDUR İLİ ALAN ARAŞTIRMASI}

\subsection{Araştırmanın Amacı ve Önemi}

Bu çalışma ile Örgüt kültürü ile KOSGEB Proje tabanlı destekler arasındaki ilişki incelenmiştir. Bu kapsamda ilk olarak örgüt, kültür ve örgüt kültürü kavramları ile Örgüt Kültürünün tarihsel gelişimi, modelleri ve fonksiyonları değerlendirilmiştir. Daha sonra örgüt kültürünün KOSGEB proje tabanlı desteklere olan ilişkisi araştırılmıştır.

Çalışmada ayrıca, Burdur ilinde KOSGEB proje tabanlı destekler olan KOBİGEL KOBİ proje, ar-ge inovasyon endüstriyel uygulama ve iş birliği destek programı ile işletme geliştirme (genel) desteği alan firmaların örgüt kültürü etkinlikleri araştırılmıştır.

\subsection{Araştırmanın Kapsamı ve Kısıtları}

Araştırmanın kapsamını Burdur ilinde faaliyet gösteren KOSGEB proje tabanlı destekler olan KOBİGEL KOBİ Gelişim destek Programı (KOBİ Proje), AR-GE ve İnovasyon Destek Programı, İş Birliği Destek Programlarından faydalanan, imalat sektöründe yer alan KOBİ'ler oluşturmaktadır. Bu çalışmada veri kaynağı olarak Burdur İlinde faaliyet gösteren, imalat sektöründe KOSGEB proje tabanlı desteklerden faydalanan işletmelerin sahipleri ve profesyonel yöneticileri ele alınmıştır. Araştırmada bir takım kısıtlar ile karşılaşılmıştır. Bu kısıtlar şu şekilde belirtilebilir;

$\checkmark$ Araştırmanın sadece Burdur İlinde faaliyet gösteren KOSGEB proje tabanlı desteklerden faydalanan imalat sektörü KOBİ'leri ile sınırlandırılması,

$\checkmark$ Örnek kütle olarak seçilen KOBİ’lerin faaliyet yıllarının en az 1 yıl olması,

$\checkmark$ Verilen cevapların deneklerin algisına dayalı olmasıdır.

\subsection{Araştırma Modeli}

Bu araştırmadan KOBI'lere sağlanan proje tabanlı destekler KOBİGEL KOBİ Gelişim destek Programı (KOBİ Proje), AR-GE ve İnovasyon Destek Programı, İş Birliği Destek Programı ve Genel (işletme Geliştirme) Destek programı bağımlı değişkenler olmuştur. İşletme yaşı, destek aldığı süre, işletme türü, örgüt kültürü kavramları olan misyon, tutarlılık, katılım, dışa uyum ise bağımsız değişkenler olarak modelde yer almıştır. Bağımsız değişkenlerimizin bağımlı değişkenlerimiz üzerindeki etkisine göre KOSGEB proje tabanlı desteklerden faydalanma durumları incelenmeye çalışılmış. Kurulan fonksiyonlar lojistik regresyon modelinde çıkan sonuçlara göre yorumlanmıştır.

Şekil 3. Örgüt Kültürünün ve İşletme Demografisinin KOSGEB Desteklerine Etkisi

\begin{tabular}{ll} 
BAĞIMSIZ DEĞISSKEN \\
\hline$>\quad$ Katılım \\
$>$ Misyon \\
$>$ Dişa Uyum \\
$>\quad$ Tutarlılık \\
$>\quad$ Destek aldığı Süre \\
$>$ İşletme Türü \\
$>$ Iş̧letme Yaşı
\end{tabular}

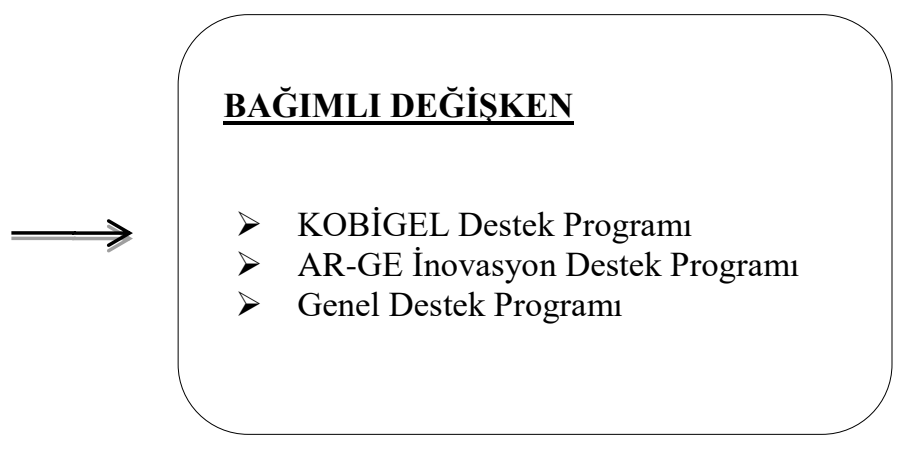




\subsection{Araştırmada İzlenen Yol}

$\mathrm{Bu}$ araştırmada, ilk olarak literatür taraması yapılmış, ayrıntılı olarak amaç ve yöntemler belirlenmiştir. Öncelikle daha önce bazı çalışmalarda kullanılmış olan bazı ölçeklerden yararlanılarak hazırlanan anket taslağı, üzerinde gerekli değişiklikler yapılarak geliştirilmiştir. Bu geliştirmeden sonra ise anket çoğaltılmıştır. Daha sonra anketler araştırma örneklemi üzerinde de uygulanmıştır. Veri işleme ve çözümleme programı olarak SPSS 20.00 istatistik programı seçilmiş ve toplanan veriler bilgisayara girilmiştir. Daha sonra veriler işlenerek istatistik çözümlemeler yapılmıştır. Bundan sonra elde edilen bulgular yorumlanarak araştırma sonucu hazırlanmıştır. Veri toplama yöntemi olarak, anket tekniği seçilmiştir. Örgüt kültürünün KOSGEB proje tabanlı destekler üzerinde etkisini araştırmak üzere oluşturulan anket formunun birinci bölümü katılımcılar ile ilgili demografik sorulardan meydana gelmektedir. Bu bölümde hukuki yapıları, firma yöneticiliği ya da sahipliği, öğrenim durumu, işletmenin hangi sektörde faaliyet gösterdiği, hangi KOSGEB desteklerini aldığı, işletme yaş1, destek aldığı yıl ile ilgili sorular yer almaktadır. Anketin ikinci bölümündeki Denison Örgüt Kültürü ile ilgili ölçeğin 60 soruluk özgün formun Türkçeye çevirisi Gökşen (2001) ve daha sonra Yahyagil'in danışmanlık yaptığı yüksek lisans tezinde İçin (2002) tarafından yapılmış, Yahyagil (2004) tarafından, yapılan son düzenlemelerle ölçeğin özgün niteliği korunarak soru sayıs1 36'ya indirgenen ve Topçu'nun (2014) y1lında yaptığı yüksek lisans çalışmasından yaralanarak hazırlanmıştır. Kullanılan ölçekler 5'li likert tipinde olup; 1: kesinlikle katılmıyorum, 5: kesinlikle katılıyorum ölçek aralığında değerlendirilmiştir. İşletmelerin örgüt külttürü yapıları ve eğilimleri hakkında misyon, katılım, tutarlılık ve dışa uyum ile ilgili Daniel Denison çalışmalarından yararlanılarak hazırlanan sorular KOBI'’lere yöneltilmiştir.

Konu ile ilgili literatür taraması yapıldıktan sonra hazırlanan, anket formları, ilgili işletmeler ziyaret edilerek ve araştırma için oluşturulan anket formunun bulunduğu "http://www.surveey.com/SurveyStart.aspx?lang=1\&surv=a681dbdd37b34767a550782626702cbc" web adresi katılımcılara e-mail yoluyla ulaştırılmış ve linkten ilgili sayfaya erişim sağlanarak anketi cevaplandırmaları istenmiştir. E-mail yolu ile anketleri cevaplandırmaları talep edilen, Burdur İlinde örneklemimizde yer alan 41 işletmenin tamamına ulaşılmış, hepsinden geri dönüş alınabilmiştir. Anketler işletmenin işletme sahipleri ve üst yöneticiler tarafindan cevaplandırılmıştır. Araştırmanın bu bölümünde, geliştirilmiş olan ölçme araçlarından elde edilen verilerin, SPSS 20.00 programı ile frekans, güvenilirlik analizleri yapılmış, lojistik regresyon modeli ile elde edilen sonuçlarda ortaya çıkan bulgular ve yorumlar sunulmuştur.

\subsection{Demografik Özelliklerine İlişkin Bulgular ve Yorumlar}

Bu çalışmada, Burdur ilinde imalat sanayinde faaliyet gösteren 41 firma ile örgüt kültürü ve KOSGEB proje tabanlı destekleri arasındaki ilişkiler araştırılmıştır. Anket yöntemi ile toplanan verilerle, örneklemin \%58,5'i işletme sahibi, $\% 41,5^{\prime} \mathrm{i}$ ise profesyonel yöneticidir. Katılımcıların cinsiyetlerine göre dağılımı ile işletmedeki katılımcıların \%87,8'ini erkek, \%12,2'sini ise bayanlar oluşturmuştur. Bayanların \%80'i işletme sahibi olup, \%20'si profesyonel yöneticidir. Erkeklerin ise \%55,6's1 işletme sahibi olup \%44,4'ü profesyonel yöneticidir. Katılımcıların \%43,9'u lisans; \%24,4'ü lise mezunu olup Burdur ilinde imalat sanayinde faaliyet gösteren firmaların yaklaşık \%68'i en az lise mezunu kişiler tarafından yönetilmektedir. İşletmelerin \%63,4'ü limited şirket, \%26,8'i şahıs ve \%7,3'ü ise anonim şirket türündedir. Firmaların \%40'1 5 ile 8 yıl; \%32,5'i 1 ile 4 yıl ve \%25'i 9 ile 12 yıl arası destek almaktadır. Destek almaya başlayan firmaların \%72,5 oranla 2011-2019 yılları arasında yer almasının, 2010 yılında güncellenen KOSGEB destek programlarının daha ulaşılabilir, hızlı ve etkin olduğu ifade edilebilir.

Destek alan işletmelerin türlerine göre limited şirketlerin \%42,3'nün 5 ile 8 yıl; \%34,6's1 1 ile 4 ve \%19,2'si 9 ile 12 yıl arasında destek aldığını göstermektedir. Klasik işletme yaşam döngüsü olarak değerlendirdiğimizde limited şirketlerin \%42 ile en fazla desteği kullanma eğilimlerinin işletmenin büyüme dönemlerine rastladığg görülmektedir. Büyüme dönemlerinde rakiplere karşı Pazar payını koruyarak portföyünü arttırmaya çalışmaları KOSGEB desteklerine ihtiyaç duyduklarını, işletmeler olgunlaşma dönemlerine geldiklerinde KOSGEB desteklerine ihtiyacın ve ilginin azaldığını ifade edebiliriz. Şahıs işletmelerinde ise desteğe duyulan ihtiyaç ve ilginin kuruluş dönemindeki sermaye yetersizliğiyle daha fazla talep gördüğü tahmin edilmektedir. Şahıs işletmelerinde ortaya çıkan sonuç limitet şirketlere göre daha uzun vadede yaklaşık olarak eşit şekilde ihtiyaç duyulduğu ancak uzun dönemde bu desteğe olan ihtiyacın azaldığı ya da yok olduğu şeklindedir. Anonim şirketler ise bu desteklere 5 ile 12 yıl arasında ihtiyaç duymaktadır. 
KOSGEB tarafından işletmelere verilen KOBİGEL, AR-GE ve Genel desteklerin işletme türlerine göre dağılımı ise tablo 27'de yer almaktadır. KOBİGEL desteğinin büyük bir payının limitet şirketlere verilmiş olduğu görülmüş̧ür. Bu durumdan limitet şirketlerde örgüt kültürünün daha iyi oturduğu, belli bir disipline ulaşmış işletmelerce proje tabanlı desteklerin daha iyi takip edilip, süreci hatasız yürütüp kullandıkları sonucuna varılabilir.

Şahıs işletmelerinin en çok AR-GE İnovasyon destek programına yöneldiği görülmüştür. Bu durumun nedeni, Burdur ilinde şahısların arge projeleri geliştirerek projelerinin kabul edilmesinden sonra yönetimi, hukuki prosüdürü basit ve riski az olan şahıs işletmeleri açmak istemeleri ile açıklanabilir. KOBİGEL ve genel desteğin şahıs işletmelerine ayrılan payları yaklaşık \%15 civarındadır. Bu desteklerin kullanımının düşük olmasının sebebinin şirketlerin kuruluş aşamasında, yaşam döngülerinin henüz başlarında olmaları ve süreçlerin takibindeki zorluk olduğu düşünülmektedir.

Anonim şirketlerinin aldıkları destek paketlerinden en fazla paya KOBİGEL desteği sahip çıkmıştır. ARGE ve genel desteğin anonim şirketlere ayrılan payları yaklaşık \%7'ler civarındadır. Bunun nedeni ülkemizdeki genel ARGE tutumuyla açıklanabilir. Belli bir sermaye büyüklüğüne ve insan kaynağına ulaşmış olduğunu düşündügümüz anonim şirketlerin daha fazla ARGE ve inovasyon faaliyetleriyle ilgilenmeleri gerektiğini düşünebiliriz. Anonim şirketlerin genel destek paylarının düşük olmasının nedeni ise işletme geliştirme(genel) destek programındaki destek oran ve üst limitlerinin düşük, görece evrak işlemlerinin çok olmasından dolayı enerji ve personellerini daha farklı gelir getirici alanlarda kullanmak istemeleri olduğu düşünülebilir. Dolayısıyla Burdur ilinde verilen proje tabanlı desteklerin çoğunluğu projede kendi sorumluluğuna düşen finansal kısmı karşılayabilecek sermaye açısından yeterli; büyüme isteğini, Pazar payı ve ürün çeşitliliğini artıracak imkânı KOSGEB proje tabanlı destekleriyle daha hızlı sonuçlandıracak limitet şirketler kullanmıştır. Limitet şirketlerini şahıs işletmeleri ve anonim şirketler takip etmektedir.

Denison ölçeğine ait katılım, tutarlılık, dışa uyum ve misyon alt ölçeklerine ait $\alpha$ değeri 0.913 olup sekiz maddeden; tutarlılık alt ölçeğine ait $\alpha$ değeri 0.952 olup ve beş maddeden; dişa uyum ölçeğine ait $\alpha$ değeri 0.852 olup yedi maddeden ve misyon ölçeğine ait $\alpha$ değeri 0.897 olup yedi maddeden oluşmaktadır. Örgüt kültürünü oluşturan ölçeklerin hesaplanmasında, bu maddelerin aritmetik ortalaması alınarak analizlere devam edilmiştir.

Tablo 2. Modeldeki Bağımlı ve Bağımsız Değişkenlerin Açıklaması

\begin{tabular}{|c|c|}
\hline Değişken Adı & Açıklaması \\
\hline KOBİGEL & $\begin{array}{l}\text { İşletme, KOSGEB tarafindan verilen KOBİGEL desteği aldıysa 1, almadıysa } \\
0 \text { değerini alan kukla değişken }\end{array}$ \\
\hline$A R G E$ & $\begin{array}{l}\text { İşletme, KOSGEB tarafindan verilen ARGE desteği aldıysa } 1 \text {, almadıysa } 0 \\
\text { değerini alan kukla değişken }\end{array}$ \\
\hline Genel Destek & $\begin{array}{l}\text { İşletme, KOSGEB tarafından verilen Genel Destek desteği aldıysa } 1 \text {, } \\
\text { almadıysa } 0 \text { değerini alan kukla değişken }\end{array}$ \\
\hline Katılım & $\begin{array}{l}\text { Denison ölçeği yardımıyla Burdur İli’ndeki işletmelerin örgüt kültürü alt } \\
\text { ölçeği olan Katılım değişkeni }\end{array}$ \\
\hline Tutarlılık & $\begin{array}{l}\text { Denison ölçeği yardımıyla Burdur İli’ndeki işletmelerin örgüt kültürü alt } \\
\text { ölçeği olan Tutarlılık değişkeni }\end{array}$ \\
\hline Dışa Uyum & $\begin{array}{l}\text { Denison ölçeği yardımıyla Burdur İli'ndeki işletmelerin örgüt kültürü alt } \\
\text { ölçeği olan Dışa Uyum değişkeni }\end{array}$ \\
\hline Misyon & $\begin{array}{l}\text { Denison ölçeği yardımıyla Burdur İli’ndeki işletmelerin örgüt kültürü alt } \\
\text { ölçeği olan Misyon değişkeni }\end{array}$ \\
\hline İşletme Yaşı & İşletmenin yıl cinsinden faaliyet gösterdiği süre \\
\hline Destek Aldığı Süre & KOSGEB tarafından kaç yıldır destek aldığını gösteren değişken \\
\hline İşletme Türü & $\begin{array}{l}\text { Sermaye İşletmesi (LTD.ŞTİ+A.Ş.) için 1; Şahıs İşletmesi (Şahıs+diğer) için } \\
0 \text { değerini alan kukla değişken }\end{array}$ \\
\hline
\end{tabular}


Fonksiyonel ilişki kurulan modellerdeki açıklanan değişken nitel olduğu için tahmin yönteminde nitel tercih modellerinden biri olan lojistik regresyon modeli ile tahminler yapılmıştır. Tablo 3'de lojistik regresyona ait tahmin sonuçları yer almaktadır. Tahmin sonuçlarına göre bağımlı değişkenin Genel Destek olduğu modelde, örgüt kültürünün alt ölçeklerinden sadece dışa uyum istatistiksel olarak anlamlı olup, diğer kurum kültürü ölçekleri istatistiksek olarak anlamlı bulunmamıştır.

Tablo 3. Logit Model Tahmin Sonuçları

\begin{tabular}{|c|c|c|c|}
\hline \multirow{2}{*}{ Katsayı } & \multicolumn{3}{|c|}{ Bağımlı Değişken } \\
\hline & KOBİGEL & ARGE & GENEL DESTEK \\
\hline$\beta_{0}$ & $\begin{array}{c}1.386 \\
{[0.53]}\end{array}$ & $\begin{array}{l}-1.334 \\
{[-0.56]}\end{array}$ & $\begin{array}{l}-5.187 \\
{[-1.43]}\end{array}$ \\
\hline$\beta_{1}$ & $\begin{array}{l}1.460 \\
{[1.14]}\end{array}$ & $\begin{array}{l}-0.542 \\
{[-0.46]}\end{array}$ & $\begin{array}{c}1.525 \\
{[1.18]}\end{array}$ \\
\hline$\beta_{2}$ & $\begin{array}{l}0.625 \\
{[0.86]}\end{array}$ & $\begin{array}{l}-1.394 \\
{[-1.49]}\end{array}$ & $\begin{array}{l}-1.053 \\
{[-0.84]}\end{array}$ \\
\hline$\beta_{3}$ & $\begin{array}{l}-1.054 \\
{[-1.10]} \\
\end{array}$ & $\begin{array}{l}0.462 \\
{[0.38]} \\
\end{array}$ & $\begin{array}{c}-1.997 * * * \\
{[-1.72]}\end{array}$ \\
\hline$\beta_{4}$ & $\begin{array}{l}-1.709 \\
{[-1.50]} \\
\end{array}$ & $\begin{array}{l}1.709 \\
{[1.24]} \\
\end{array}$ & $\begin{array}{c}2.261 * * * \\
{[1.63]}\end{array}$ \\
\hline$\beta_{5}$ & $\begin{array}{l}0.045 \\
{[1.17]}\end{array}$ & $\begin{array}{c}-0.075 * * \\
{[-2.02]}\end{array}$ & $\begin{array}{c}0.0162 \\
{[0.54]}\end{array}$ \\
\hline$\beta_{6}$ & $\begin{array}{l}0.007 \\
{[0.07]} \\
\end{array}$ & $\begin{array}{c}0.199 * * * \\
{[1.90]}\end{array}$ & $\begin{array}{l}-0.051 \\
{[-0.58]} \\
\end{array}$ \\
\hline$\beta_{7}$ & $\begin{array}{c}1.676^{* * *} \\
{[1.97]}\end{array}$ & $\begin{array}{l}-1.029 \\
{[-1.36]}\end{array}$ & $\begin{array}{c}1.625 \\
{[1.41]}\end{array}$ \\
\hline $\mathrm{R}^{2}$ & 0.191 & 0.215 & 0.163 \\
\hline $\mathrm{LR}-\chi^{2}$ & $\begin{array}{c}8.08 \\
(0.325)\end{array}$ & $\begin{array}{c}10.07 \\
(0.184)\end{array}$ & $\begin{array}{c}5.91 \\
(0.549)\end{array}$ \\
\hline Log-Likelihood & -21.758 & -21.122 & -22.024 \\
\hline
\end{tabular}

$*, * *, * * *$ sirasıyla, $0.01,0.05$ ve 0.10 anlamlılık düzeyinde istatistiksel olarak anlamlıdır.

$\mathrm{Bu}$ sonuçlara göre KOBİGEL'in bağımlı değişken olduğu modelde misyon ve işletme türü değişkenleri istatistiksel olarak anlamlı bulunmuştur. Diğer değişkenler sabitken misyon değişkenindeki bir birimlik artış KOBİGEL desteği alma olasılığını 0.303 birim azaltırken, sermaye işletmelerinin şahıs işletmelerine göre KOBİGEL desteği alma olasılığ 0.297 birim daha fazladır.

ARGE'nin bağımlı değişken olduğu modelde, diğer değişkenler sabitken tutarlılıktaki bir birimlik artış, ARGE desteğini alma olasılığını 0.241 birim azaltırken; destek aldığı yıldaki bir birimlik artış ARGE desteğini alma olasılığını 0.034 birim arttırmakta ve işletmenin yaşındaki bir birimlik artış ARGE desteğini alma olasılığını 0.013 birim azaltmaktadır.

Son olarak genel desteğin bağımlı değişken olduğu modelde diğer değişkenler sabitken, misyondaki bir birimlik artış genel destek alma olasılığını 0.416 birim arttırmakta ve dışa uyumdaki bir birimlik artış genel destek alma olasılığını 0.368 birim azaltmaktadır. Sermaye işletmelerinin şahıs işletmelerine göre genel destek alma olasılığ 0.299 birim daha fazladir. 
Tablo 4. Logit Modelinden Elde Edilen Marjinal Etkiler

\begin{tabular}{|c|c|c|c|}
\hline \multirow{2}{*}{$\begin{array}{c}\text { BAĞIMSIZ } \\
\text { DEĞíşKEN }\end{array}$} & \multicolumn{3}{|c|}{ BAĞIMLI DEĞIŞKEN } \\
\hline Katsayı & KOBİGEL & ARGE & GENEL DESTEK \\
\hline \multirow{2}{*}{ Katılım } & 0.259 & -0.094 & 0.281 \\
& {$[1.25]$} & {$[-0.46]$} & {$[1.28]$} \\
\hline \multirow{2}{*}{ Misyon } & $-0.303 * * *$ & 0.296 & $0.416^{* * *}$ \\
& {$[-1.67]$} & {$[1.32]$} & {$[1.76]$} \\
\hline \multirow{2}{*}{ Dışa Uyum } & -0.187 & 0.080 & $-0.368^{* * *}$ \\
& {$[-1.15]$} & {$[0.37]$} & {$[-1.76]$} \\
\hline \multirow{2}{*}{ Tutarlılık } & 0.111 & $-0.241^{* * *}$ & -0.194 \\
& {$[0.89]$} & {$[-1.65]$} & {$[-0.89]$} \\
\hline \multirow{2}{*}{ Destek Aldığı Süre } & 0.001 & $0.034 * *$ & -0.009 \\
& {$[0.07]$} & {$[2.15]$} & {$[-0.58]$} \\
\hline \multirow{2}{*}{ İşletme Türü } & $0.297 * *$ & -0.178 & $0.299 * * *$ \\
& {$[2.53]$} & {$[-1.52]$} & {$[1.65]$} \\
\hline \multirow{2}{*}{ İşletme Yaş1 } & 0.008 & $-0.013 * *$ & 0.003 \\
& {$[1.26]$} & {$[-2.17]$} & {$[0.55]$} \\
\hline
\end{tabular}

$*,{ }^{* *},{ }^{* * *}$ sirasıyla, $0.01,0.05$ ve 0.10 anlamlılık düzeyinde istatistiksel olarak anlamlıdır.

Elde edilen sonuçlar birlikte incelendiğinde katılım ölçeği KOSGEB destekleri üzerinde istatistiksel olarak anlaml tahmin edilememiştir. Misyon ölçeği KOBİGEL ve Genel Destek üzerinde istatistiksel olarak anlamlı bir etkiye sahiptir. Örgüt kültüründeki gelişmişlik seviyesinin arttığı bu misyon ölçeğindeki alt başlıklara baktığımızda stratejik yönlendirme, temel amaçlar ve vizyon etkilidir.

İşletme geliştirme (genel destek) programında ve özelliklede KOBİGEL proje çağrılarında desteğe başvurma, projeyi yürütme ve desteği alma süreçlerini yürütebilecek işletmelerin stratejik yönlendirilmesi önemlidir. Çünkü örgüt amaçlarının ulaşılabilirliğini artırmak için çok açık şekilde çizilmiş iş-stratejilerinin mevcudiyeti ve bu yönde inançlı bir tutuma sahip olunması işletmenin desteği sorunsuz bir şekilde almasında etkili olmayacaktır. Örgüt üyelerinin vizyon sahibi olarak değerlendirilmesi uzak geleceğe dönük ancak anlamlı, net olarak belirlenmiş örgüt vizyonları çalışanların sinerjisini yükseltmekte, işletmenin temel amaçları doğrultusunda yaptıkları işleriyle bütünleşmesini sağlamaktadır. Bu proje desteğinde hazırlanan başvuru formunda ve projenin kabul edilmesinden sonra ulaşılması gereken hedefler ve amaçların ne zaman, nerede, nasıl, kiminle sorularını cevaplamakta ve işletme başarısını arttırmaktadır.

Dışa uyum sadece genel destek üzerinde istatistiksel olarak anlamlı bulunmuştur. Denison örgütsel kültür modelinde dışa uyum alt başlıklarını değerlendirmek gerekirse değişim yaratma, müşteri odaklılık ve örgütsel öğrenme oluşturmaktadır. İşletme Geliştirme (genel) destek programında ilimizde en çok kullanılan destekleri gözlemlediğimizde yurt içi fuar, yurt dışı iş gezisi ve nitelikli eleman desteği yer almaktadır. Sürekli değişen ve gelişen uluslararası pazar ve rakipleri takip etmek için yurt dışı iş gezilerini, müşterilerin istek, ihtiyaç ve beklentilerin öğrenilmesi ve karşılanması için katılınan yurt içi fuarları, teknolojik ve modern teknik, beceri ve tecrübelerin örgüt içine yerleştirilmesi ve entegresi için kullanılan nitelikli eleman desteğini daha açılanabilir kılmaktadır. Tutarlılık ise sadece ARGE desteği üzerinde istatistiksel olarak anlamlı bulunmuştur.

Modelimizde tutarlılık başlığının altındaki temel değerler uzlaşma, koordinasyon ve entegrasyon bulunmaktadır. AR-GE ve inovasyon faaliyeti yürüten işletmelerin örgüt yapısının bu özellikleri barındırması önemlidir. Temel değerler kuruluş aşamasında kurucular tarafından belirlenen temel değerleri kapsar. Uzlaşma, koordinasyon ve entegrasyon ise örgüt üyelerinin işletme amaçlarına ve bu amaçlara ulaşırken ki düşünce, eylem, karar alma ve işi yapma birlikteliklerinin uyumunu vurgular. 


\section{SONUÇ}

$\mathrm{Bu}$ çalışmada amaç, Burdur İlinde faaliyet gösteren ve KOSGEB proje tabanlı desteklerinden faydalanan KOBİ'lerin, destek alma süreçlerinde işletme örgüt kültürünün ve demografik özelliklerinin etkisi ortaya koymaktır. Elde edilen sonuçlara göre KOBİGEL'in bağımlı değişken olduğu modelde, misyon ve işletme türü değişkenleri istatistiksel olarak anlamlı bulunmuştur. Diğer değişkenler sabitken misyon değişkenindeki bir birimlik artış, KOBİGEL desteği alma olasılığını 0.303 birim azaltmıştır. Bunun nedeninin Denison örgüt kültürü modelinde ifade edilen misyon kültürünün alt başlıkları olan hedef, vizyon ve stratejik yönelim kabiliyeti yüksek olan firmaların amaçlarına ulaşmakta kullandıkları yol haritalarını kurgularken uzun dönemli iş zaman planlarına yayıp ihtiyaç duydukları kavramların planlamasını çok önceden yapması; buna karşılık kobigel proje desteğinin çağrı dönemlerinin her yıl farklı tarihte ve kapsamda ilan edilip çağrı başvuru süresinin de kısa tutulması nedeniyle planlamalarında KOSGEB kobigel desteğinin yer almaması olduğu düşünülmektedir.

Sermaye işletmelerinin (A.Ş. ve Ltd. Şti.) şahıs işletmelerine göre KOBİGEL desteği alma olasıllı̆ı 0.297 birim daha fazladır. Bunun nedeni KOBİGEL çağrılarında yer alan başvuru kriterlerinin şahıs şirketlerinden çok sermaye şirketlerine uygun olmasıdır. ARGE'nin bağımlı değişken olduğu modelde, diğger değişkenler sabitken;

- Tutarlılıktaki bir birimlik artış, ARGE desteğini alma olasılı̆̆ını 0.241 birim azaltmaktadır. Bunun nedeni ARGE faaliyetlerinin ruhunun farklı düşünme ve eylem kabiliyetiyle ilişkili olmasıdır. Örgüt içerisindeki fikir birliğinin ARGE çalışmalarını engellediği düşünülmektedir.

- Destek aldığı yıldaki bir birimlik artış ARGE desteğini alma olasılığını 0.034 birim arttırmaktadır. Bunun nedeni olarak KOSGEB desteği almaya başlayan firmalarda destek yönetmelikleri ile ilişkili farkındalığın artması ve desteğin etkinliğinin anlaşılmaya başlamasıyla ARGE inovasyon desteğine yönelerek faaliyetlerini arttırmak istemeleri olduğu ifade edilebilir.

- İşletmenin yaşındaki bir birimlik artış, ARGE desteğini alma olasılığını 0.013 birim azaltmaktadır. Burdur ilinde işletme yaşındaki artışın ARGE inavasyon desteğini azaltmasının sebebi, ARGE inovasyon desteği alan işletmelerin girişimci düzeyinde bu desteğe başvurup projesi kabul edildikten sonra işletmenin kuruluşunun yasal prosedürlerinin başlaması ve desteğe başvurmasından kaynaklanmaktadır. ARGE inovasyon desteğine ilginin en yoğun olarak girişimci adayları olan üniversite öğretim elemanları ve işletmelerde görev yapan personellerden olduğu gözlemlenmiştir. Diğer bir durum ise işletmelerin yaş1 arttıkça gelir getirici faaliyetlerinin rutine bağlanması, mevcut sorun ve üretim teknolojilerine yenilikçi çözümler getirmekten ziyade var olan genel kabul görmüş çözümleri dış kaynaklardan ve tedarikçilerden satın alma eğiliminde olmaları şeklinde ifade edilebilir.

Son olarak, genel desteğin bağımlı değişken olduğu modelde, diğer değişkenler sabitken;

- Misyondaki bir birimlik artış genel destek alma olasılığını 0.416 birim arttırmaktadır. Örgüt kültüründe misyon kavramı işletmenin planlı amaç ve hedeflerinin olması ve uzun dönemli iş planlarına göre çalışan ve yöneticilerin karar almasıdır. İşletme Geliştirme (genel) destek programında yer alan destek kalemleri incelendiğinde yurt içi fuar, nitelikli eleman, test analiz belgelendirme gibi desteklerinin işletmenin planlamasında önceden tahmin edilip icraata geçirebileceği ve başvuru yapabileceği destek kalemleri olmasından dolayı misyon etkinliğinin yüksek olduğu ifade edilebilir.

- Dışa uyumdaki bir birimlik artış, genel destek alma olasılığını 0.368 birim azaltmaktadır. Bunun nedeni ise bu destek kalemlerinde yer alan yurt içi fuar, yurt dış1 iş gezisi, nitelikli eleman desteğini alan işletmelerde dışa uyum tutumunu arttırdığı, alınan desteklerin başarılı olduğu ve tekrar kullanılmasına gerek olmadığı düşünülebilir.

- Sermaye işletmelerinin şahıs işletmelerine göre genel destek alma olasılığı 0.299 birim daha fazladır. Genel destek programı her ne kadar proje yazma kapasitesine sahip olmayan işletmelere yönelik olarak kurgulanmış olsa da analiz sonucunda desteğin içeriği ve hitap ettiği kesim daha profesyonel olan sermaye şirketlerine yöneliktir.

Denison örgüt kültürü modelinde ifade edilen misyon kavramındaki artışın KOBİGEL proje destek programından yararlanma olasılığını azaltırken, Genel Destek programından yararlanma olasılığını arttırdığı, işletme türünde ise sermaye işletmelerini KOBİGEL proje desteği ve genel destek programlarından yararlanma olasılığını arttırdığı, dışa uyum kültürünün ise genel destek programlarından yararlanma olasılığını azalttığı 
tespit edilmiştir. İşletmelerde tutarlılık kültürü ve işletme yaşındaki artış ARGE desteği alma olasılığını azaltırken destek aldığı yıldaki artışı ARGE desteğini alma olasılığını arttırdığı tespit edilmiştir.

$\mathrm{Bu}$ çalışmanın bulgu ve sonuçları doğrultusunda gelecekte araştırma yapmak isteyen araştırmacılara katkı sağlaması yönünde öneri olarak; daha farklı il veya bölgelerde ve diğer destek programı gibi farklı nitelikte ve ölçekte araştırmalar yapılabilir.

\section{KAYNAKÇA}

AR, Mahmut (2009), “KOBI'lere Verilen Teşvik ve Destekler Kapsamında KOSGEB Konya Örneği”, Yayınlanmamış Yüksek Lisans Tezi, Karamanoğlu Mehmetbey Üniversitesi Sosyal Bilimler Enstitüsü, Karaman.

AYKAÇ, Mustafa ve PARLAK, Zeki (2008), Küreselleşme Sürecinde Rekabet Gücünün Artırılması ve Türkiye'de KOBİ'ler, İstanbul Ticaret Odası Yayını, İstanbul.

BAKIR, Lütfullah (2019), “Örgüt Kültürünün ve İşletme Demografisinin Kosgeb Desteklerine Etkisi: Burdur Illi Araştırması", Yayınlanmamış Yüksek Lisans Tezi, Mehmet Akif Ersoy Üniversitesi Sosyal Bilimler Enstitüsü, Burdur.

CANSIZ, Mehmet (2008), “Türkiye'de KOBI'ler ve KOSGEB”, Devlet Planlama Teşkilatı Uzmanlık Tezi, DPT Yayını, Ankara.

CILLOV, Haluk (1954), “Türkiye'de Sanayi İstatistikleri”, İstanbul Üniversitesi İktisat Fakültesi Mecmuası, S.16(1), ss.176-196.

ÇAKIROĞLU, Deniz (2008), “Japonya Ülke Raporu”, E-Rapor, https://besbogda.files.wordpress.com/2011/06/japonya.pdf, (Erişim Tarihi: 12.05.2018).

DEMIRBİLEK, Tunç (2005), İş Güvenliği Kültürü, Legal Yayıncılık, İzmir.

DENISON, Daniel R. ve MiSHRA, Aneil K. (1995), "Towards A Theory of Organizational Culture and Effectiveness", Organization Science, S.6(2), ss.204-223.

DERİN, Neslihan, DEMIREL, Erkan Turan ve POLAT DEDE, Nurten (2013), “Verimliliği Artırma ve Rekabet Önceliği Elde Etmede Önemli Bir Teknik: Yalın Girişim”, Tunceli Üniversitesi Sosyal Bilimler Dergisi, S.2(3), ss.60-80.

ERKMEN, Turhan (2010), Örgüt Kültürü, İşletmelerin Başarısındaki En Temel Paradigma, Beta Yayınevi, İstanbul.

GÖKŞEN, Ufuk (2001), “Diagnosing Organizational Culture in the Army”, Yayınlanmamış Yüksek Lisans Tezi, Bilkent Üniversitesi Sosyal Bililimler Enstitüsü, Ankara.

GÜVENÇ, Bozkurt (1996), İnsan ve Kültür, Remzi Kitabevi, İstanbul.

GÜVENÇ, Bozkurt (2003), Kültürün ABC'si, Yapı Kredi Yayınları, İstanbul.

KARAKOÇ, Ahmet (2010), "KOSGEB Kaynakl Kobi Destekleri ve Bütçe İlişkisinin Değerlendirmesi", Yayınlanmamış Yüksek Lisans Tezi, Hacettepe Üniversitesi Sosyal Bilimler Enstitüsü, Ankara.

KOÇEL, Tamer (2001), İşletme Yöneticiliği, Beta Yayınları, İstanbul.

KOSGEB (2010), KOSGEB Stratejik Planı (2011-2015), KOSGEB Yayını, Ankara, https://www.kosgeb.gov.tr/content/upload/dosya/mali\%20tablolar/kosgebn\%20stratejik\%20plan/kosgeb_ stratejik_plani_(2011-2015).pdf (Erişim Tarihi: 12.01.2018).

KOSGEB (2017), Performans Programı, KOSGEB Yayını, Ankara, https://www.kosgeb.gov.tr/site/tr/genel/detay/349/plan-raporlar-ve-mali-tablolar (Erşim Tarihi: 25.08.2018).

KOSGEB (2018), 2017 Yılı KOSGEB Faaliyet Raporu, KOSGEB Yayını, Ankara, https://www.kosgeb.gov.tr/content/upload/dosya/mali\%20tablolar/kosgeb_2018_y\%c4\%b11\%c4\%b1_faal iyet_raporu.pdf (Erşim Tarihi: 22.09.2018). 
LEIDNER, Dorothy E., ALAVI, Maryam ve KAYWORTH, Timothy R. (2008), "The Role of Culture in Knowledge Management: A Case Study Of Two Global Firms", Knowledge Management: Concepts, Methodologies, Tools, and Applications (Ed. M. E. Jennex), IGI Global Press, Hershey, ss.2112-2131.

MADEN, Selen Işık (2012), “KOGEB Genel Destek Programının Firmalar Üzerindeki Etkilerinin Değerlendirilmesi: Göller Bölgesi Uygulaması”, Yayınlanmamış Doktora Tezi, Süleyman Demirel Üniversitesi Sosyal Bilimler Enstitüsü, Isparta.

MECEK, Gülsevil (2020), “Küçük ve Orta Büyüklükteki İsletmelerin (KOBİ) Uluslararası Tanımlama Ölçütleri ve Kavramlaştırılması", Ekonomi İșletme Siyaset ve Uluslararası İlișkiler Dergisi (JEBPIR), S.6(1), ss.29-55, https://dergipark.org.tr/tr/download/article-file/1166793 (Erişim Tarihi: 03.05.2020).

MURAT, Güven ve AÇIKGÖZ, Banu (2007), "Yöneticilerin Örgüt Kültürü Algllamalarına İlişkin Bir Analiz: Zonguldak Karaelmas Üniversitesi Örneği”, ZKÜ Sosyal Bilimler Dergisi, S.3(5), ss.1-20.

MÜFTÜOĞLU, Tamer (2002), Türkiye'de Küçük ve Orta Ölçekli İşletmeler, Turhan Kitapevi, Ankara.

ÖZKALP, Enver ve KIREL, Çiğdem (1996), Örgütsel Davranış, Anadolu Üniversitesi Yayınları, Eskişehir.

SCHEIN, Edgar H. (1992), "How Can Organizations Learn Faster? The Problem of Entering The Green Room", Invited Address to the World Economic Forum, 06.02.1992 - Davos (Switzerland), ss.118, https://core.ac.uk/download/pdf/4380058.pdf (Erişim Tarihi: 22.09.2018).

SCHWARTZ, Howard ve DAVIS, Stanley M. (1981), "Matching Corporate Culture and Business Strategy", Organizational Dynamics, S.10(1), ss.30-48.

STEPHEN, Robbins ve JUDGE, Timothy (2009), Organizational Behavior, Prentice Hall, New Jersey.

ŞIŞMAN, Mehmet (1994), Örgüt Kültürü: Eskişehir İl Merkezindeki İlkokullarda Bir Araştırma, Anadolu Üniversitesi Yayınları, Eskişehir.

TOPÇU, Aygül (2014), “Kamu ve Özel Sağlık Kuruluşlarında Performans Yönetimi Uygulamalarının Kurumsal Kültür Boyutunda Değerlendirilmesi”, Yayınlanmamış Yüksek Lisans Tezi, Hasan Kalyoncu Üniversitesi Sosyal Bilimler Enstitüsü, Gaziantep.

UZUN, Dilek (2007), “Örgüt Kültürünün Bilgi Yönetim Sürecine ve Örgütsel Performansa Etkisi: Beş Yıldızlı Otel Işsletmelerinde Bir Uygulama", Yayınlanmamış Doktora Tezi, Dokuz Eylül Üniversitesi Sosyal Bilimler Enstitüsü, İzmir.

YAHYAGIL, Mehmet Y. (2004), "Denison Örgüt Kültürü Ölçme Aracının Geçerlik ve Güvenirlik Çalışması: Ampirik Bir Uygulama", İstanbul Üniversitesi İşletme İktisadı Enstitüsü Yönetim Dergisi, S.47, ss.53-76.

http://www.chusho.meti.go.jp/sme_english/outline/02/01.html (Erşim Tarihi: 22.09.2018).

http://www.resmigazete.gov.tr/eskiler/2005/11/20051118-5.htm (Erşim Tarihi: 25.09.2018).

http://www.tuik.gov.tr/prehaberbultenleri.do?id=15881 (Erşim Tarihi: 22/09/2018). 